\title{
Aproximación teórica del objeto de estudio del turismo
}

\section{Theoretical approximation to matter of tourism study}

\author{
Aníbal Fuentes Moreno ${ }^{1}$ \\ ${ }^{1}$ Universidad Central del Ecuador. Facultad de Ciencias Agrícolas. Carrera de Turismo Ecológico. \\ Jerónimo Leiton y Av. La Gasca s/n. Ciudadela Universitaria. Quito. 170521. Ecuador
}

\section{Resumen}

La construcción del conocimiento del turismo ha sido tema básico de diversos investigadores que se reconocen como pioneros de la teoría del turismo, tales como Morgensten, Erenspergel, Glücksmann, Borman, Troisi, Guyer-Freuler, Stradner, además de los connotados turismólogos Hunzinker y Krapf. Dichos autores propusieron, hacia 1942, la Doctrina General del Turismo (DGT) bajo un enfoque disciplinar económico y sociológico, que enfatizó que los visitantes en los 50 eran motivados por su amor al patrimonio cultural especialmente en Europa. Gran parte de los estudios en los 50 y 60 se limitaron al análisis de la demanda y sus variables en gustos, preferencias de compra y diversión, fortalecidos por un creciente interés en las técnicas de promoción, publicidad y comercialización, lo que sería el nacimiento del mercadeo (marketing). Contemporáneos como Luis Fernández Fuster, Manuel Ortuño Martínez, Manuel Ramírez Blanco o bien Oscar de la Torre Padilla, entre otros, han influido en hacer notar que el turismo posee una ciencia que se origina por la teoría desarrollada respecto a este fenómeno y a su práctica. En los 80 Fernández Fuster iniciaría una publicación preguntándose: ¿Es el turismo una ciencia?, provocando no pocas discrepancias que, para aquel tiempo, en donde las ciencias iniciaban su especialización y perfeccionamiento, el planteamiento de la pregunta, se convertiría en un problema de prestigio, agregando que tal fenómeno tiene hasta hoy día, un sinnúmero de conocimientos con entidad propia, suficiente para que pueda reclamar la categoría de disciplina científica. Sin embargo, las discusiones académicas en el siglo XXI sobre si el turismo es una ciencia o no, están a la orden del día entre los investigadores, académicos, pedagogos y organismos públicos y privados. En este sentido, la pregunta ¿Es el turismo una ciencia?, se vuelve viral en procesos de rediseños curriculares que apuntan a un cambio de matriz productiva en el Ecuador.

Palabras clave: turismo, sostenible, desarrollo sostenible, sistema turístico, cultura, conservación, epistemología, objeto de estudio, ciencia.

\begin{abstract}
Knowledge construction of tourism has been the subject of several basic researchers who are recognized as pioneers of the theory of tourism such as Morgenstern, Erenspergel, Glücksmann, Borman, Troisi, Guyer-Freuler, besides the notorious Stradner turismólogos Hunzinker and Krapf, who proposed to the 1942 General Doctrine of Tourism (DGT) under a discipline of economic and sociological approach, which emphasized that the 50 visitors were motivated by their love of cultural heritage especially in Europe. Much of the study in the 50's and 60's were limited to the study of variables in demand and tastes, purchasing and entertainment preferences, reinforced by a growing interest in the techniques of promotion, advertising and marketing, which would be the birth of marketing (marketing). Contemporaries as Luis Fernandez Fuster, Manuel Ortuño Martinez, Manuel Ramirez White or Oscar Padilla Torre, among others, have influenced noting that tourism has a science that originates by the theory developed on this phenomenon and practice. In the 80 Fernandez Fuster begin a post wondering: Is tourism a science?, causing no little disagreement that for that time where science began their specialization and refinement, the approach to the question would become a matter of prestige, adding that such a phenomenon has until today, a number of knowledge of its own, enough to be able to claim the status of scientific specialization. However, 21 st century academic discussions about whether
\end{abstract}


tourism is a science or not, are the order of the day among researchers, academics, educators and public and private agencies. In this sense, the question, Is tourism a science? becomes viral in curricular redesign processes aimed at changing production matrix in Ecuador.

Keywords: Tourism, sustainable, sustainable development, tourism system, culture, conservation, epistemology, under study science.

\section{Introducción}

El primer elemento que confirma que el turismo es una actividad real se halla en la ley francesa, del 20 de junio de 1936, en donde se señala que todo ciudadano francés tiene derecho al tiempo libre y para garantizarlo el patrono debe pagarle; es decir, el trabajador dispondrá de dinero en su tiempo libre. En 1946 la constitución francesa instituyó de nuevo el derecho al descanso, donde se sugirió que dicho tiempo podía ser utilizado en actividades que requieran un desplazamiento fuera de su lugar de residencia habitual. Allí es donde se puede apreciar como el concepto turismo adquiere características para ser considerado un hecho turístico. Más adelante, en 1961, se certifica al turismo como un hecho de naturaleza especial en la "Carta Social Europea", donde se interpreta por primera vez al turismo como un hecho fundamental. En 1966 aparece en el "pacto internacional de los derechos sociales y culturales" donde se consagra el derecho al turismo como hecho social y el derecho al descanso como necesidad humana. En 1976 se consagra al turismo como un hecho social en la constitución portuguesa. Posteriormente, en 1978 el turismo es concebido como un hecho social en la constitución de lengua castellana en España. En los 90 cada país, cada región, cada continente iniciaría un sinnúmero de declaratorias todas ellas direccionadas a defender y fortalecer el derecho a realizar turismo como un hecho social, derecho al descanso, códigos de ética, identidad y protección del patrimonio cultural y natural, todo esto respaldado por organismos mundiales como la UNESCO, BID, OEA, OIT, OMT. En 2001 el turismo es reconocido como prioridad nacional en el Ecuador. Finalmente, en 2007, el turismo sostenible es reconocido como política de estado.

\section{Etimología del turismo}

El turismo es en la práctica, una actividad de servicios personales, motivados por conocer territorios distintos a los de nuestro lugar habitual de vida que ofertan servicios de alojamiento, alimentación, animación y transporte tan variado como el gusto del consumidor. Sin embargo, la descripción del turismo expuesta en el primer párrafo, no significa que es la única o la más acertada, pues algo que ha caracterizado al turismo con el paso de los años, es la gran variedad de definiciones, caracterizaciones y enfoques. Se analiza a continuación algunos conceptos históricos, en una primera aproximación de averiguar el origen del turismo para posteriormente entrar con el análisis de la epistemología y objeto de estudio.

En la Teoría Sajona, palabra del Sajón antiguo Torn (Inglaterra), se desprenden de este los vocablos Torn-us (lo que da vueltas) y Torn-are (dar vueltas). Esa raíz implicaba una partida con regreso, y se utilizó durante el siglo XII en los viajes de descanso que emprendían los campesinos. En sajón, los sustantivos de origen del verbo son denominados con el sufijo -er (writ-er - Speak-er). Se presupone que aquel que viaja y luego regresa a su lugar de origen fue llamado Torn-er. En el siglo XVIII se sustituye el término er por el latín iste y griego isme, para luego en el siglo XX alcanzar la denominación de tour-ist (e) y la actividad que de su acción deriva bajo Tour-ism. En castellano, ambos adquieren la denominación de turismo y turista en el mismo siglo; esta es la consideración de la escuela latina (Fernández Fuster, 1978; Boyer, 1982; Jiménez Guzmán, 1986).

Dentro de la escuela Semítica: Houlot (1961) asevera que el término turismo no deriva de la lengua latina, sino del arameo antiguo. Según este autor, en este idioma se utilizaba el término Tur para los viajes, la exploración y el traslado de personas.

La escuela Onomástica, de origen inglés, considera que el origen del concepto turismo no se encuentra en una raíz lingüística sino que está vinculado a un apellido de la aristocracia francesa, De la Tour. La prueba empírica a esta hipótesis se encuentra cuando Carlos V en 1516 firma un tratado de relaciones con Inglaterra. Al celebrar dicho con- 
venio, el rey le entrega la exclusividad del transporte comercial a una familia aristócrata llamada De la Tour. Neil Leiper sostiene que esta familia organizó los primeros viajes de comerciantes ingleses al continente, hecho que marcó el principio del turismo como actividad orientada al desplazamiento comercial (Jiménez Guzmán, 1986; Leiper, 1983).

A mediados del siglo XX, la Teoría Turística se fortalece y algunos turismólogos contemporáneos determinan cinco corrientes básicas, aplicadas al turismo:

- Corriente económica: El turismo como un hecho económico, donde se aprovecha los recursos o bienes de tipo económico. La importancia del turismo radica en el beneficio económico que puede dejar la región receptora en donde se lo practica (Schullern, 1911).

- Corriente cinética: El turismo como un hecho de movimiento. El turismo es un movimiento de personas que abandonan temporalmente su residencia habitual por motivos relacionados con su espíritu, su cuerpo y su profesión. El turismo es un conjunto de viajes cuyo objeto principal es el comercio, el placer y la profesión (Schwink, 1929; Bormann, 1930).

- Corriente sico-social: El turismo como un hecho social que se produce en los seres humanos por la actividad turística. El turismo es un gráfico de viajeros de lujo, es decir, de aquellos que abandonan su residencia habitual y se dirigen a otro sitio sin ningún fin económico, sino para incrementar su "status" y satisfacer necesidades de lujo. Ya se da aquí una noción elitista del turismo como actividad propia de una clase social (Stradner, 1920). El turismo es una actividad que lleva el tráfico de personas que abandonan su lugar de residencia habitual hacia otro sitio y allí satisfacer necesidades de diversa índole (Morgenroth, 1929).

- Corriente de la definición: El turismo es un fenómeno que se puede definir por su género próximo y su diferencia específica. Entonces la corriente de la definición afirma que el contenido del turismo es definitivo, que no cambia con la historia y que los elementos que se encuentran en el contenido del turismo son inmodificables (son exponentes de esta corriente Piero Barucci, Alberto Bertolini, Kurt Krapf, Walter Hunziker y Alberto Sessa). Esta corriente se sustenta en determinadas condiciones que lo hacen posible:

- El desplazamiento, con la única finalidad de recreación y descanso (loisir).

- La transferencia de ingresos que es para Barucci, la esencia o el epicentro de la actividad turística.

- $\quad$ El gasto en loisir, o sea en actividades propias del tiempo libre

- $\quad$ El viajero.

Barucci (1976) no llega a concretar una definición al turismo, pero sostiene que toda definición que se haga de turismo debe partir de estos cuatro elementos. Para 1974, Alberto Bertolino propone los aspectos fundamentales del turismo:

- $\quad$ El desplazamiento.

- $\quad$ El aspecto económico.

- El aspecto moral, esto se refiere a la vocación que tiene el turista de viajar y gastar para presumir socialmente un estatus económico.

- Un tiempo homogéneo, que recoge todos los momentos destinados.

Bertolino define al turismo como una libre transferencia de personas y réditos, entre países y localidades, originada durante un tiempo en el cual se realizan actos particulares de consumo.

- Corriente de la descripción: El turismo es un fenómeno descriptible, se hace imposible definirlo por su género próximo y por su diferencia específica, porque los elementos del contenido del turismo han cambiado con el tiempo, son evolutivos. Sería un gravísimo error definir con los valores sociales de hoy y para siempre, algo que mañana seguramente va a cambiar, no hay que olvidar que el turismo es un hecho socio-económico dinámico, susceptible y cualquier cambio que se haga en el tiempo modificará el contenido del turismo (son exponentes de esta corriente Salah Wahab, Marc Boyer, y John Heeley). 
- Desde el punto de vista de la relación social y humana, se puede decir que el turismo es el encuentro de pueblos, de culturas y mentalidades y es por lo tanto un hecho social.

- Desde el punto de vista del mundo exterior, el turismo se caracteriza por ser una industria, o sea un proceso productivo que contribuye al desarrollo de los países del tercer mundo.

- $\quad$ Desde el punto de vista del sujeto receptor, el turismo se caracteriza por ser una profesión que se rige por reglas principios éticos y por técnicas especiales.

Se podría decir entonces que el turismo depende de quién lo mire y cómo lo mire.

\section{Escuelas y tendencias}

\subsection{Escuela humanística del turismo}

El turismo para esta escuela es ante todo un hecho humano que no busca resultados económicos, sino que se basa en la utilización de los atractivos turísticos para su recreación y descanso. Los autores que fundamentan esta teoría son Walter Hunziker y Kurt Krapt. Según ellos, el turismo es un conjunto de relaciones y fenómenos que se producen por el desplazamiento y permanencia de personas fuera de su lugar de residencia habitual sin fines de lucro. No obstante, la escuela humanística es una escuela tradicional y a partir de ella se van formando una serie de postulados que trascienden el contenido un tanto individual y abstracto de lo humano y ubicado en el campo de lo "social".

\subsection{Escuela sociológica del turismo}

Para esta escuela lo que se da en el turismo no es solo un hecho humano sino una relación de índole social o una relación de grupos de personas o de grupos sociales. En 1978 la asociación internacional de expertos científicos en el turismo (AIEST) modifica el concepto turismo definiéndolo como un hecho social humano, económico y cultural irreversible. Uno de los autores que fundamenta estas teorías es Alfonso Flórez Esparragoza (1979), quien dice que la humanidad tiene claro lo que es el turismo, por eso el turismo es un hecho social innegable previo a cualquier consideración de lucrativo. A este respecto hay que mencionar tres tendencias:

\section{Tendencia sociológica}

En esta tendencia el turismo se ha convertido en un problema social, ya que las personas en vez de socializar por medio de la actividad turística se están convirtiendo en seres antisociales. Hay dos formas de entender el problema, una positiva y una negativa. Para la tendencia positiva, el turismo es un problema social pero solucionable en el momento en el que el ser humano se comporte como tal. Para la tendencia negativa, el turismo ante todo es elemento de la súper-estructura ideológica del sistema social, esta permite la reproducción amplia del capital para las multinacionales a costa de las necesidades de países del tercer mundo.

\section{Tendencia geográfica}

En esta tendencia se concibe al turismo como un problema social por lo inelástico de la oferta, por la rigidez del espacio para el turismo y por el daño que se le está haciendo por no tener en cuenta la planificación.

\section{Tendencia económica}

En esta tendencia el turismo ya ha dejado de ser un hecho social y se ha convertido en un hecho económico.

\section{Epistemología del turismo}

"A medida que un campo de estudio evoluciona hacia su madurez se introducen y se persiguen nuevas medidas bien fundadas que traslucen una progresión sucesiva y señalan el camino para la transición deseada. Una visión global ilustraría de forma general ese trayecto que se va cubriendo en este ámbito turístico hasta adquirir el estatus de ciencia" (Jafari, 2000).

La cientificización del turismo, término acuñado por el turismólogo Jafar Jafari en su tesis doctoral, provocó no pocos comentarios a favor y en contra, especialmente en el mundo de la academia, en donde se presta mucha atención a las razones de por qué esta disciplina no es considerada seriamente por las disciplinas ya establecidas, pero a su vez, existe atracción por las formas sociales que envuel- 
ven a la actividad. Se discute también si el gran número de trabajos de titulación, revistas, artículos y productos turísticos son suficientes para la consolidación del turismo como ciencia (Korstanje, 2011).

Jafari (2005) intenta responder primero a la trivialización y la segunda a la indisciplina y disgregación del conocimiento generado. Para muchos pedagogos Jafari no tomó en cuenta la evolución histórica de las diferentes ciencias ni tampoco su vinculación con los sistemas económicos desde donde esas disciplinas nacían.

Tribes (2010) considera que uno de los principales problemas del turismo es su falta de cohesión para poder lograr paradigmas unificados regulados por una academia de naturaleza internacional.

Jafari concluyó erróneamente que una disciplina se mide por la producción bibliográfica ignorando las bases esenciales de toda ciencia. Si bien debemos admitir, esta creencia se encuentra muy expandida en los diversos trabajos en turismo, debe ser reconsiderada seriamente.

El brasileño José Renato de Castro Cesar analiza el turismo desde seis apartados:

- el turismo a través del viaje;

- el turismo como sujeto y objeto de la misma estructura;

- el turismo como contenido de percepción;

- el turismo como identidad de contenido;

- el turismo como percepción de objetos, concluyendo con

- el turismo como una escuela de pensamiento.

\section{Objeto de estudio del turismo}

Analizado la etimología y la epistemología del turismo desde la visión de pedagogos, científicos y turismólogos, se propone el siguiente objeto de estudio: El turismo es la ciencia que estudia el espacio turístico en conjunto con el patrimonio natural y cultural, el escenario en donde se desenvuelven los grupos humanos y su inter-relación con el paisa- je; interpreta la organización económica, política, ambiental y cultural de la sociedad observada desde un punto de vista geométrico como un conjunto de localidades, infraestructuras de transporte, tecnologías y comunicación, uso sostenido de los recursos naturales, flujos migratorios, modelando el desarrollo y organización del destino turístico.

Este objeto de estudio integra cinco componentes o núcleos estructurantes que sustentan la ciencia del turismo, así: la administración, el patrimonio natural, el patrimonio cultural, el territorio y la operación turística; cada componente está integrado por subcomponentes que respaldan la estructura curricular científica del turismo.

\section{El turismo como ciencia}

Independientemente de la discusión sobre si el turismo es o no ciencia existen algunas cuestiones que son pertinentes analizarlas tales como ¿qué significa desarrollar investigaciones científicas en turismo?, ¿qué sustenta la cientificidad de esas investigaciones?, o ¿si es posible establecer una metodología de la investigación para el turismo? En otras palabras, ¿hay un método científico propio para las investigaciones en turismo, o se pueden aplicar abordajes metodológicos de otras áreas del conocimiento? ¿Qué abordajes serían esos? ¿Qué metodología de la investigación puede desarrollarse para la educación en turismo? ¿Cuál es la relevancia de la investigación y de la iniciación científica en la formación del profesional en turismo? ¿Qué implicaciones podría tener la capacitación en investigación en el perfil del profesional del turismo? Responder con claridad estos cuestionamientos es esencial para el docente, para el pedagogo, para el investigador turístico y para el estudiante que anhela ser un profesional del turismo en el siglo XXI.

Sin duda alguna el principal problema al analizar si el turismo es o no ciencia, es que muchos de los autores que hoy publican, estudian y trabajan en turismo, no han tenido como formación una licenciatura en turismo, guianza, hospitalidad, menos aún gastronomía y más bien su formación se limita a las áreas de administración, arquitectura, biología, comunicación, derecho, economía, filosofía o geografía, además, muy pocos o ninguno ha trabajado directamente en la operación turística, en animación a grupos, en interpretación de naturaleza, en el front desk de un hotel, en una cocina, en un aeropuerto, 
con nacionalidades indígenas $\mathrm{y}$, por supuesto, no han asistido turísticamente a visitantes reales, no han oído quejas ni tampoco felicitaciones de visitantes satisfechos; no han hecho un trueque con nativos, o han visto el atardecer en una laguna amazónica.

Estos hechos parecerían no ser importantes en el momento de definir al turismo como ciencia, pero constituyen una limitación en el estudio del turismo pues el investigador tiende inconsciente y en ocasiones conscientemente a reducir la explicación del turismo a su ámbito de especialidad o una experiencia turística vivida.

\section{Conclusiones}

El turismo no se lo puede estudiar de manera independiente, requiere de apoyo de las demás ciencias, por ser una actividad obligatoriamente de interrelación humana.

Si bien el hombre desde su aparición sobre el planeta Tierra exploró, viajó y descubrió territorios, su motivación fue la supervivencia y el poder a di-

\section{Referencias}

Barucci, P. (1976) Tourism: ¿the end of myth? Centro di studi turistici . Italia.

Bormann, A. (1930). Lehre vom Fremdenverkehr: Ein Grundriss. Verkehrswissenschaftliche Lehrmittelgesellschaft bei d. Deutschen Reichsbahn. Berlín, Alemania.

Boyer, M. (1982). Le turisme. Edition du Senil, Collection Peuple et Culture. Paris, Francia.

Esparragoza, A. (1979). Derecho turístico colombiano. CNT (Comision Nacional de Televisión). Bogotá, Colombia.

Fernández Fuster, L. (1978). Teoría y técnica del turismo. Hispano-Europea. Madrid, España.

Houlot, A. (1961). Le turisme et la Biblie. Revue l'Académie Internationale du Turisme. Mónaco.

Jafari, J. (2000). Encyclopedia of tourism Routledge, London and New York.

Jafari, J. (2005). El turismo como disciplina científica. Política y Sociedad, 42(1), 39-56. ferencia del placer, el descanso, el estatus, el stress y más motivaciones que convierten al viajar en turismo.

El definir si el turismo es ciencia o una actividad de servicios dependerá de los resultados que investigadores y pedagogos demuestren a través de métodos y resultados científicos, que aún no han sido totalmente satisfactorios, desde la visión centralizada de físicos, matemáticas, geógrafos y arquitectos.

\section{Recomendaciones}

Las redes de turismo deben incluir en sus actividades académicas anuales, conversatorios y eventos científicos que traten con seriedad el tema.

Los organismos de control estatal como Ministerio de Turismo, Quito Turismo, consejos provinciales, y privados como cámaras de turismo, agencias de viaje, hoteles deben participar activamente en las definiciones de ciencia o actividad de servicios como aporte a su actividad.

Jiménez Guzmán, L.F. (1986). Teoría turística: un enfoque integral del hecho social. Universidad Externado de Colombia. Bogotá, Colombia.

Korstanje, M.E. (2011). Nociones básicas de epistemología para el turismo. TURyDES, 5(12).

Leiper, N. (1983). An etimology of tourism. Annals of tourism research (2). Pergamon Press. New York, USA.

Morgenroth, W. (1929). Fremdenverkehr, En: von Elster Ludwig Adolf Weber \& Friedrich Wieser (eds.) Handwörterbuch der Staatswissenschaft. Ledereinband. Alemania.

Schullern, H. (1911). Turismo y economía nacional. Austria.

Schwinh, (1929). Die Bedeutung des Fremdenverkehrs fuer die Bayerische Wirt rev. Monatliche Mitteüungen des Bundes deutscher Verkehrsvereine. Alemania.

Tribes, J. 2010. Tribes, territories and networks in the tourism academy. Annals of Tourism Research, 37(1), 7-33. 